\title{
How to promote electromobility for European car drivers? Obstacles to overcome for a broad market penetration
}

\author{
Jan-André Bühne ${ }^{1}$ - Dana Gruschwitz ${ }^{2}$ Jana Hölscher ${ }^{2}$ - Matthias Klötzke ${ }^{3}$. \\ Ulrike Kugler $^{3} \cdot$ Christoph Schimeczek $^{3}$
}

Received: 27 December 2014 / Accepted: 3 August 2015 / Published online: 2 September 2015

(C) The Author(s) 2015. This article is published with open access at SpringerLink.com

\begin{abstract}
Introduction Electric vehicles can be a successful mobility alternative, but several obstacles and challenges have to be overcome first. Especially the customers' purchase decision determines whether an innovation like electromobility will be eventually successful. The objective of this paper covers the investigation of consumer's attitude towards electric vehicles and their opinion on potential promotion measures and its impact on market penetration scenarios in different countries. Methods The aforementioned issues were investigated via a European wide online consumer survey. It was designed to identify the awareness of potential consumers of electric cars as well as to discover their attitude towards this new technology. In addition to the picture of potential demand-related obstacles, the consumers were asked to evaluate the suitability of various promotion measures. Finally, the findings were included in an agent based vehicle market model which specifies consumer demand and market supply of electromobility scenarios.

Results The results show that the consumer attitude towards electromobility is rather positive and electric vehicles are generally perceived as environment-friendly and secure. But the
\end{abstract}

This article is part of the Topical Collection on Driving Societal Changes towards an Electro-mobility Future

Jan-André Bühne

buehne@bast.de

1 Federal Highway Research Institute (BASt), Brüderstraße 53, D-51427 Bergisch Gladbach, Germany

2 Institute for Applied Social Sciences (infas), Friedrich-Wilhelm-Str. 18, D-53113 Bonn, Germany

3 German Aerospace Center (DLR) - Institute of Vehicle Concepts, Pfaffenwaldring 38-40, D-70569 Stuttgart, Germany high acquisition costs and the uncertainty about the operating costs deter consumers from purchasing an electric car. First results of the inclusion of potential promotion measures such as financial incentives in a scenario based market model show a significant increase of the electric vehicle uptake in Germany.

Conclusions Potential customers have high expectations regarding the comfort and range of an electric vehicle. One of the most important barriers and obstacles for a broad market uptake are the currently high purchase prices for this new technology. Therefore, it seems quite necessary to make electric vehicles from a customer's standpoint more attractive. From the customer's perspective a dense network of charging stations and financial measures such as tax and energy cost reductions are vital prerequisites in order to convince them to buy an electric vehicle. Finally, it has been proven within a scenario based market model for Germany that the use of different promotion measures by the national government can enhance the market share of electric vehicles substantially until 2030.

Keywords Electric cars · Consumer survey · Market penetration $\cdot$ Market obstacles

\section{Introduction}

The market introduction and penetration of electric vehicles can be seen as a milestone in order to reduce the environmental burden imposed by the transport sector. The wide-spread use of electric vehicles powered by electricity from renewable sources promises a substantial reduction of local emissions in urban areas as well as greenhouse gas emissions (GHGs). The European Commission (EC) is aiming at a reduction of $20 \%$ of GHGs by 2030 with respect to 2008 . This aim still implies 
an $8 \%$ raise compared to the baseline year 1990 and refers to the substantial increase in transport and transport emissions in the past two decades [1]. In order to achieve this ambitious goal, the EC White Paper: "Roadmap to a Single European Transport Area - Towards a competitive and resource efficient transport systems" proclaimed the goal of halving the use of 'conventionally-fuelled' cars in urban transport by 2030.

Electric driven vehicles offer a solution to reduce greenhouse gas emissions and local air pollution, but their market penetration is still marginal. In order to identify the market potential as well as adjusting screws to overcome current obstacles for a further deployment of electric vehicles, the eMAP project (electromobility - scenario based Market potential, Assessment and Policy options) has been initiated within the ERA-NET Plus transnational call Electromobility+in 2012. Electric vehicles in the project as well as in this paper are defined as plug-in hybrid electric vehicles (PHEV), range extended electric vehicles (REEV), and battery electric vehicles (BEV).

The project eMAP concentrates on the analysis and assessment of the market penetration of electric vehicles and its socio-economic impacts. In this process feasible deployment paths of electric vehicles are investigated for the time horizon until 2025-2030. This is done by a scenario based market model which specifies the demand potential and market supply of electromobility. As a major input for the scenario modelling and calculation of potential market penetration paths of electric vehicles until 2030, a consumer survey was completed by the end of 2013 [2]. In order to identify the demand-related obstacles and potential impacts of imperfect information as well as for the formulation of political support measures and strategies for the market uptake of electric vehicles more than 6,000 online interviews from all over Europe have been conducted. The results of this consumer survey are presented within this article with regard to EU wide answers as well as certain country specific characteristics. Finally, a brief impression is given of the impact of a specific set of policy measures on the market penetration of electric vehicles in Germany until 2030.

\section{Obstacles for the market penetration of electric vehicles}

The widespread deployment of electric vehicles in the EU depends on a large variety of factors. To be a successful mobility alternative several obstacles and challenges have to be overcome first. Various studies identified the following main obstacles and challenges for a broad market penetration [3-5]:

- Battery technology (costs, energy density, recycling etc.)

- Availability and preparedness of relevant industrial capacity (business models, new vehicle models etc.)
- Charging infrastructure (minimum density of charging points, identification of early adopter hotspots etc.)

- Customers' requirements (awareness, willingness-to-pay, range anxiety, safety concerns etc.)

- Electric grid (capacity and connectivity issues etc.)

- Impacts on energy efficiency and green house gas emissions (electricity mix, load management etc.)

- Standardisation issues (charging plug, billing systems, data protocol etc.)

Despite the fact that the interlinkages between the aforementioned factors can play a major role for the market penetration of electric cars, the customers' requirements and expectations are the most decisive aspects for the market deployment of alternative propulsion systems. Even if the technical challenges will be resolved to a certain degree via the standardisation of the charging plug [6] and a certain minimum of charging points per country [7], the customers' purchase decision determines finally whether an innovation like electromobility will be successful or a failure on functioning markets. Therefore, this paper concentrates on demand-related obstacles and barriers for a broad market deployment of electric cars. In order to get some insight into these potential obstacles and barriers on the demand side, a European-wide consumer survey was conducted. It was designed to identify the awareness of potential consumers of electric cars as well as to give an estimate of the attitude towards this new technology. In addition to the picture of potential demand-related obstacles the consumers were asked to evaluate the suitability of various promotion measures.

\section{Potential demand related obstacles for the EV deployment}

The following chapters highlight results from the consumer survey regarding demand-related obstacles and barriers for the market penetration of electric vehicles. First of all, the framework of the conducted survey is described concerning the number of respondents and the regional boundaries. In a second step, the awareness of as well as the attitude towards electric vehicles of the interviewed persons are shown and discussed. Furthermore, the respondent's preferred car segment and the prerequisites for a positive purchase decision in favour of an electric car are illustrated. Finally, the willingness-to-pay of the respondents for a $\mathrm{CO}_{2}$ emission reduction of a new car is analysed.

\subsection{Framework of the consumer survey}

The conducted survey took place throughout the European Union (EU 28). For research efficiency reasons, it was conducted online and focused on the most populated countries 
Germany, France, the United Kingdom, Italy, Spain, Poland, Romania, the Netherlands, Greece, Belgium, Portugal, the Czech Republic, Hungary, Sweden, Austria, and Bulgaria. Finland, as one of the three partner countries of the project consortium, was also included. In each of the three focus countries (Germany, Finland, and Poland) a minimum of 1, 000 interviews were conducted, 3,000 interviews in the other 14 countries. The total number of interviews carried out in the EU was 6,025 . Target group of the survey were potential buyers and users of cars respectively. Only holders of a driving license were selected for the online survey. Respondents of the defined target group within the selected countries were sampled and contacted by a commercial online panel where potential respondents are registered. For each of the selected countries a sample was drawn aiming to represent the countries driving licence holders. The questionnaire was translated for each selected country. Therefore, each respondent was approached in his or her national language.

Aim of the survey was to learn about the customer perspective regarding electric cars. Of course it is difficult to convert answers from a questionnaire into a prognosis. Therefore, the questionnaire focused on the awareness, image and assessment of electric cars from various perspectives to reveal general patterns.

The online questionnaire consisted of six topics with a total of 42 questions. The topics of the questionnaire were:
A. Consumer background
B. Understanding of the decision making process
C. Consumer attitudes towards electromobility
D. Impact of policy and other measures
E. Cars within the household
F. Socio-demographic aspects

To obtain a balanced result for all surveyed countries regardless of the disproportional sampling - weighting was applied referring to the number of inhabitants within each country. Additionally, available structural data of driving license holders (by age and gender) from Germany, Finland, and Poland were applied in the weighting procedure. The weighting procedure within the countries refers to sociodemographic data only as there is no data available for the regional distribution of driving licence holders within the countries.

Online samples provide reliable data for countries and selected target groups when the Internet accessibility within the surveyed population is high and all groups within the surveyed population have access to the Internet and, therefore, all groups have the possibility to be included in the survey. In most EU countries the majority of the inhabitants can access the Internet. Especially in the three focus countries Germany, Poland, and Finland, the majority of the population is using Internet services at least every now and then [8]. This is true especially for Finland and, on a lower level, for Poland. For that reason this approach was chosen for the realisation of the consumer survey.

Since Internet accessibility is comparatively low in some of the surveyed countries, especially in Romania and Bulgaria, and probably not evenly distributed throughout the countries' inhabitants, an online sample is not representative for the inhabitants of the country. The sample is biased with regard to rather young inhabitants with a rather higher level of education and rather higher incomes. Nevertheless, these characteristics describe the potential target group for buying a new car. All analyses presented in this article are based on the results of the European level.

\subsection{Awareness and attitudes towards electric cars}

Petrol and diesel are the most common and also the most known energy sources for cars (see Fig. 1). The majority of respondents is also aware of electric and hybrid drives. This is especially remarkable as cars with these drives are rare on the streets. In 2012 only 109 electric cars were registered in Finland, 34 in Poland and 7,114 in Germany. This corresponds to a share of less than one percent of all registered cars within these countries [9]. Respondents are less aware of the more common LPG powered cars than of electric and hybrid cars. The high level of awareness is a good base for a market diffusion of electric drives within the EU.

Beside the respondents' awareness, their indicated expectations towards the diffusion of electric cars are high. The following Fig. 2 presents the respondents assessment of several statements concerning electric cars. For a first interpretation a vertical line is drawn between the share of respondents that (strongly) agree to the statement and those that (strongly) disagree or are rather undecided. This presentation helps to identify the share of respondents' consent.

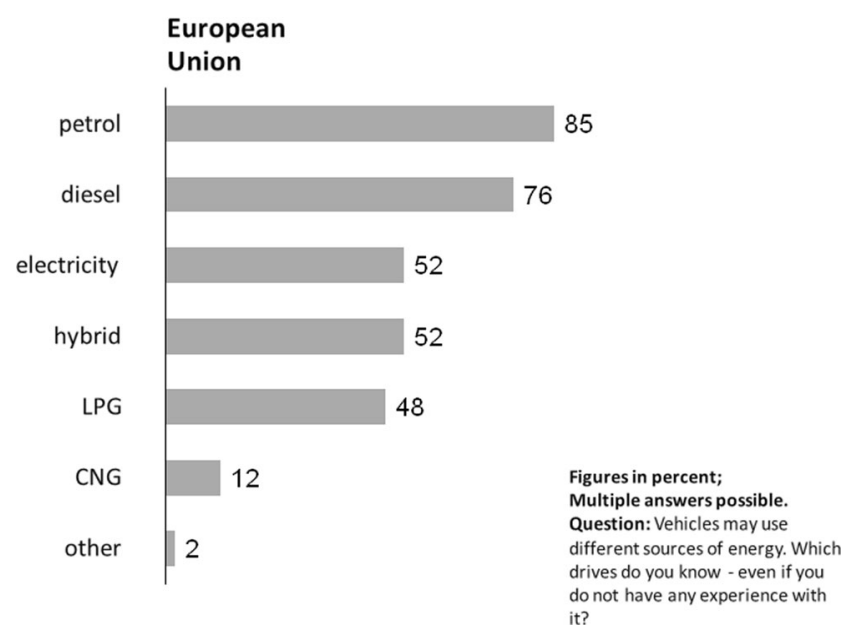

Fig. 1 Awareness of vehicle drives 
Fig. 2 Attitude towards and assessment of electric cars - EU level

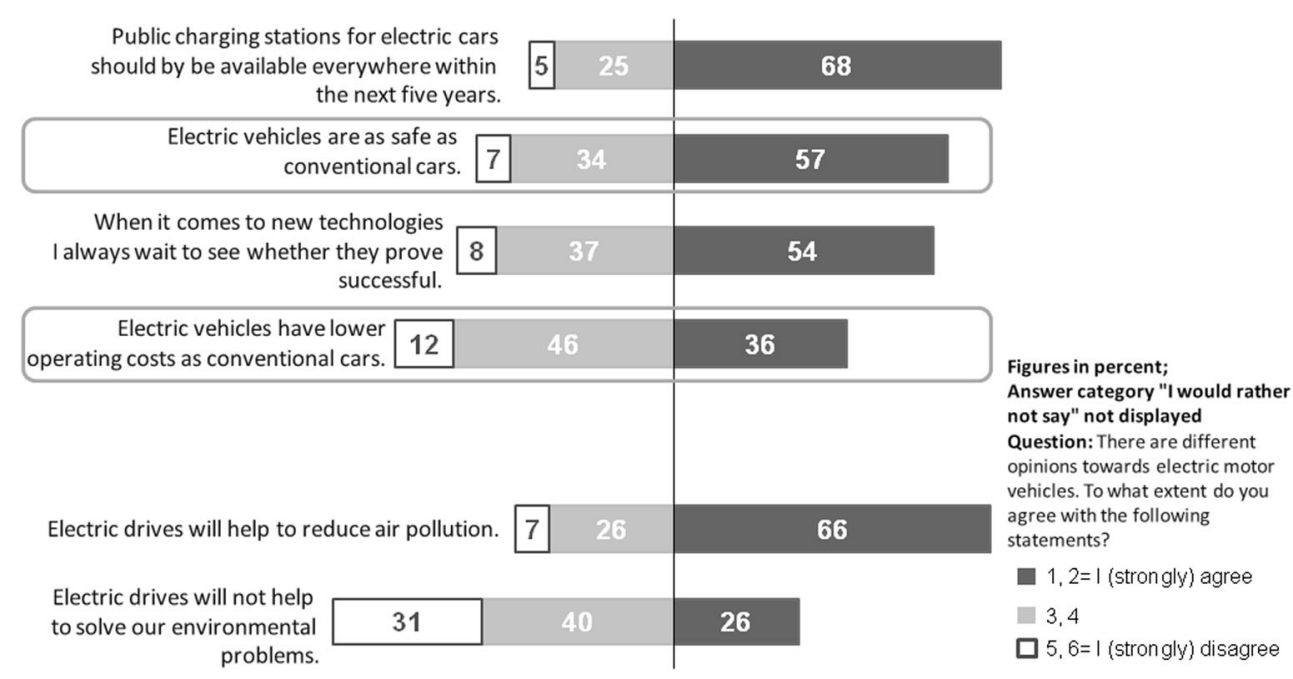

Two thirds think that public charging stations should be available everywhere within the next 5 years (see Fig. 2). The majority of respondents is confident that electric vehicles are as safe as conventional cars. Only $7 \%$ expressed to have safety concerns.

Despite of the high awareness level, the respondents are not fully informed about the costs of electric cars. One observable and commonly registered aspect is the high purchase price level of electric vehicles. An aspect which is all too often overlooked is the difference in operating costs of electric cars compared to conventional drives. This is also reflected in the consumer survey results, where only $36 \%$ think that electric vehicles have lower operating costs compared to conventional cars. This is especially true for respondents living in EU countries with lower costs for electricity. For instance, only $26 \%$ of the French respondents agree to this statement although the electricity prices in France are below the average European level. This identifies an information deficit as a potential obstacle for a broad market penetration of electric vehicles.

The results also show that a majority of the European consumers adopt a wait-and-see policy in matters of new technologies: experience, knowledge and trust are important in purchase decisions. However, there are differences in the analysed countries. Whereas a majority of German consumers adopt the aforementioned wait-and-see policy in matters of new technologies (54\%), Polish customers are more innovative since only $39 \%$ of the Polish respondents agree with the corresponding statement.

Consumers are critical about the environmental benefits of electric cars. About every fourth agrees to the statement that electric cars will not help to solve environmental problems. This is realistic with regard to the currently used electricity mix in most EU countries. Only electricity produced from renewable sources is suitable to reduce carbon emissions.
Nevertheless, the potential of electric cars to reduce (local) air pollution is recognised by two thirds of the consumers.

The stated attitudes are similar for male and female as well as for younger and older consumers. Not any consumer segment is particularly open minded or particularly anxious about electric drives. Electric cars seem to be perceived as improved or refined versions of already well known vehicles.

\subsection{Preferred cars}

Mid-size cars head the ranking of preferred car segments for everyday life; small cars are second, the percentage of light vehicles is negligible (see Fig. 3).

All in all, it illustrates that customers clearly prefer mid-size cars. This might refer to a preference for flexibility and all round cars. Mid-size cars are functional in cities due to their size and limited fuel consumption, but are convenient enough for long distances as well. In comparison, big cars, e. g., SUVs

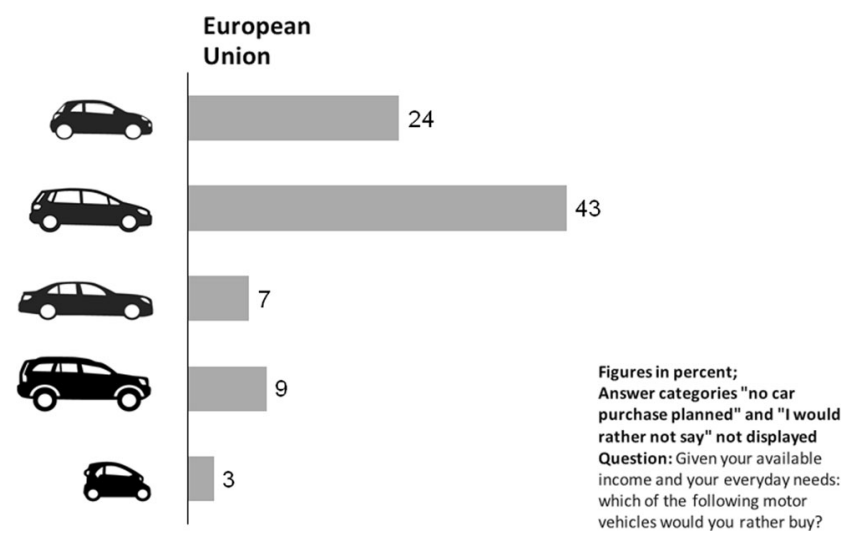

Fig. 3 Preferred car segment for everyday life 
(Sports Utility Vehicle), as well as light vehicles are not that popular.

When it comes to choosing a new or used car, low fuel consumption is the most important aspect for consumers (see Fig. 4). The vertical line in Fig. 4 - dividing respondents' answers of those (strongly) agreeing to the statement from those (strongly) disagreeing or being undecided towards the statement - helps to identify respondents consent again. The share of agreement to the other statements indicates that the importance of low fuel consumption has to be understood against the backdrop of price rather than environmental issues. Comfort and low price are crucial for the respondents' purchase decision. Almost half of the respondents are willing to choose a smaller car for environmental reasons anyway. Especially women are more often prepared to do so. Respondents living in bigger households are more reluctant when it comes to smaller cars since a smaller car might restrict flexibility for everyday life.

About one third of all consumers would drive an electric car rather than a car with combustion engine. The rejection of electric cars by one fifth, again, probably reflects the concern that electric cars are costly. About half of the respondents are indecisive with this statement. This group might be attracted by more information and suitable cars. There are no particular groups of consumers preferring electric drives over combustion engines. This reinforces the assumption that when it comes to the purchase decision, the car's drive is only one relevant feature among others. This provides a good basis for a later broader market penetration of electric drives beyond the group of early adopters.

Asked to choose between different offers of a car within their preferred car segment with equal features but differences in price and carbon emission (see Fig. 5), most respondents go for the cheapest model with the highest emissions or the model with average emissions for an average price, respectively. But there is also a group of consumers choosing a car with
Given the same features of the car which of the following models would you choose?

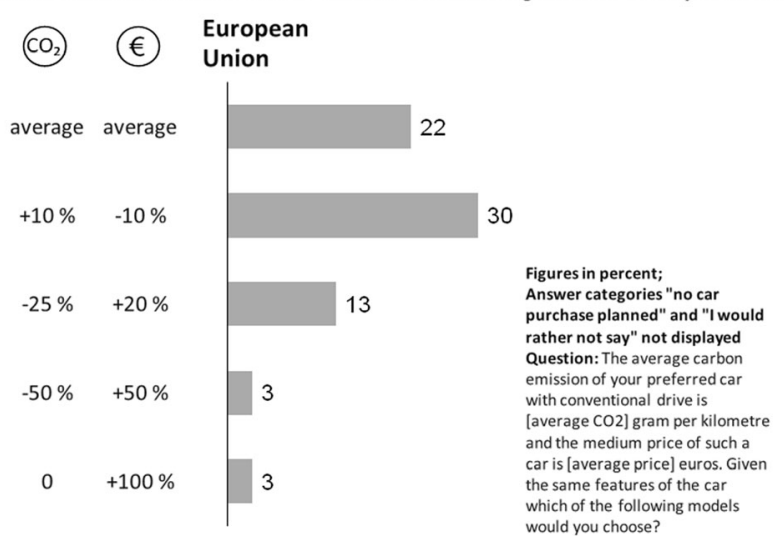

Fig. 5 Trade-off between purchase price and carbon emission

lower emissions and accepting higher asset costs for the car. This is about one fifth throughout the EU.

\subsection{Summary of demand obstacle analysis}

The results show, that consumers are generally aware of electric cars and rather open minded towards them. But the results also display that consumers prefer low cost and all-purpose cars. Electric cars offered in the EU are limited compared to conventional cars when it comes to repowering stations, range, and comfort. Since batteries are rather expensive, electric cars are more expensive to purchase than conventional cars and offer a smaller variety of models. Furthermore, if the consumer has to choose between higher prices and $\mathrm{CO}_{2}-$ emissions, most of the respondents would prefer a lower price and higher emissions. Only a small group is willing to pay a double price in order to have a car with zero $\mathrm{CO}_{2}$-emissions. All these aspects lead to a mismatch of supply, consumer expectations, and demand.
Fig. 4 Attitudes towards vehicle characteristics

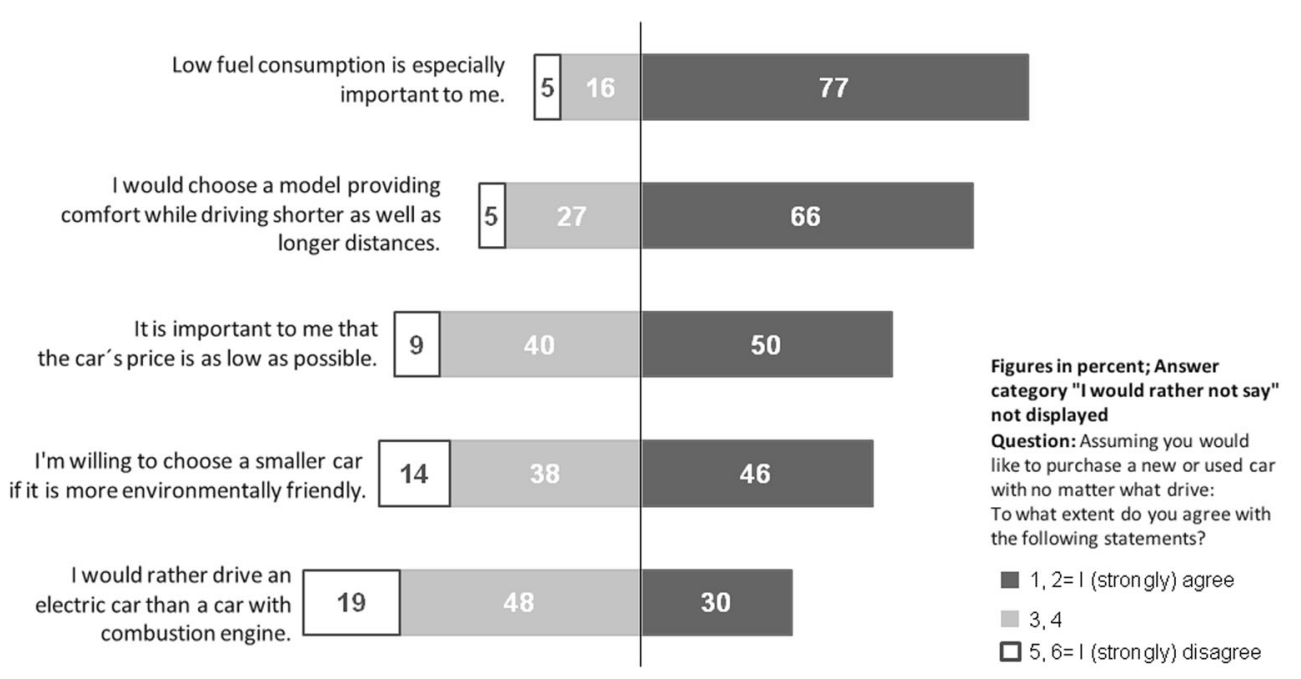




\section{Potential promotion measures from a customers' point of view}

There are several reasons to promote the market penetration of electric vehicles. The range of potential benefits goes from operating cost savings, higher efficiency, greenhouse gas emissions reductions, local air quality improvements, traffic noise reductions as well as local or national employment effects through the development and production of electric vehicles and the use of domestically-produced electricity [10].

The choice of private and governmental promotion measures includes financial measures such as fuel and registration tax exemptions, purchase bonuses [11], information campaigns, research funding, as well as urban priority measures such as the use of bus lanes and restricted parking areas for electric vehicles. In the end, the promotion measures have to meet the expectations of the consumers in order to enhance the electric vehicle fleet substantially. Successful measures have to be accepted and appreciated by the majority of consumers. Therefore, the consumer survey asked for the appraisement of a range of promotion measures. In order to resolve the mismatch mentioned above, as well as to promote electric cars, measures might be applied by the European Union, the national governments, local authorities, car manufacturers, and/ or other entities. The measures rated by the respondents to be most suitable are presented in the following Fig. 6 .

For almost two thirds of the surveyed license holders a dense network of charging stations is a vital condition for their decision to buy an electric car. Only seven percent of the respondents rate this measure as irrelevant for their decision. This essential condition is followed by the financial measures which lead to lower running costs, such as the reduction of energy costs or the annual car tax for electric vehicles. Also, a one-time bonus for the purchase of an electric vehicle is considered as an adequate measure to promote the market penetration. These four measures are vital conditions for the majority of respondents when it comes to purchasing a car.

Furthermore, the possibility to experience electric cars and go for a test ride as well as the offer of all-round and allpurpose electric cars are quite important for the respondents. However, only less than one third of the respondents see measures such as free parking in city centres, special credit offers with lower interest rates, or information campaigns as inevitable requirements for the purchase decision. Nevertheless, most of the interviewed persons regard these measures as an appropriate incentive. Overall, measures that give electric cars an advantage compared to conventional cars are welcomed by the majority of the consumers as appropriate incentives. Measures in disadvantage for conventional cars such as restricted access to certain areas in cities and an increase of fuel costs car are rather rejected by the majority of the respondents.

Results are generally similar in the observed countries and differ only in details. For example, in Finland the reduction of energy costs, lower insurance rates as well as bonus and benefits for a purchase are not as essential as in Germany and Poland. In Poland information campaigns, free parking in city centres and special credit offers with lower interest rates are more important than in Germany and Finland.

The results show that different measures are suitable to ease the consumers' purchase decision in favour of an electric car. From the consumers' point of view, there are different players with different spheres of influence who have to cooperate in order to promote electric cars successfully. The most important player is the national government with the biggest influence on annual car taxes, energy costs as well as bonuses and benefits for the purchase of an electric car (see Fig. 7). Local authorities can influence the circumstances through parking regulations, exemptions for restricted areas and the declaration
Fig. 6 Rating of possible measures to push electric cars

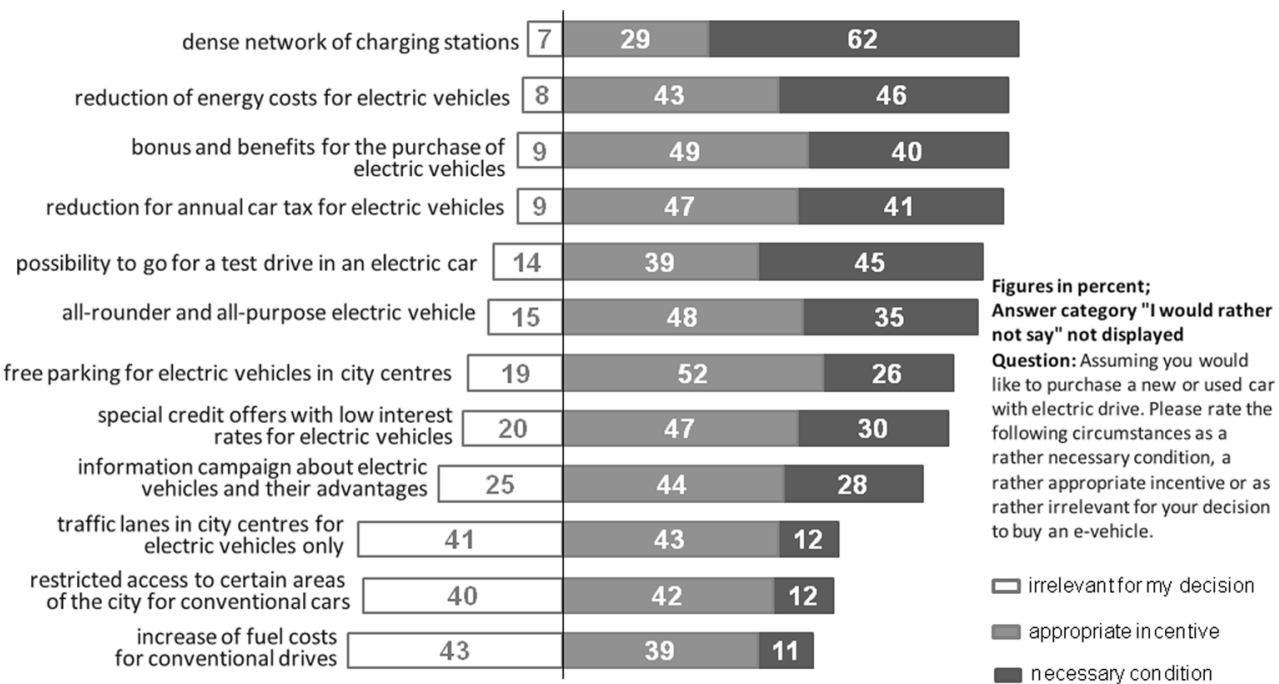


Fig. 7 Most important promoters of possible measures
Figures in percent; Respondents, who think that the "item" is a necessary condition or appropriate incentive.

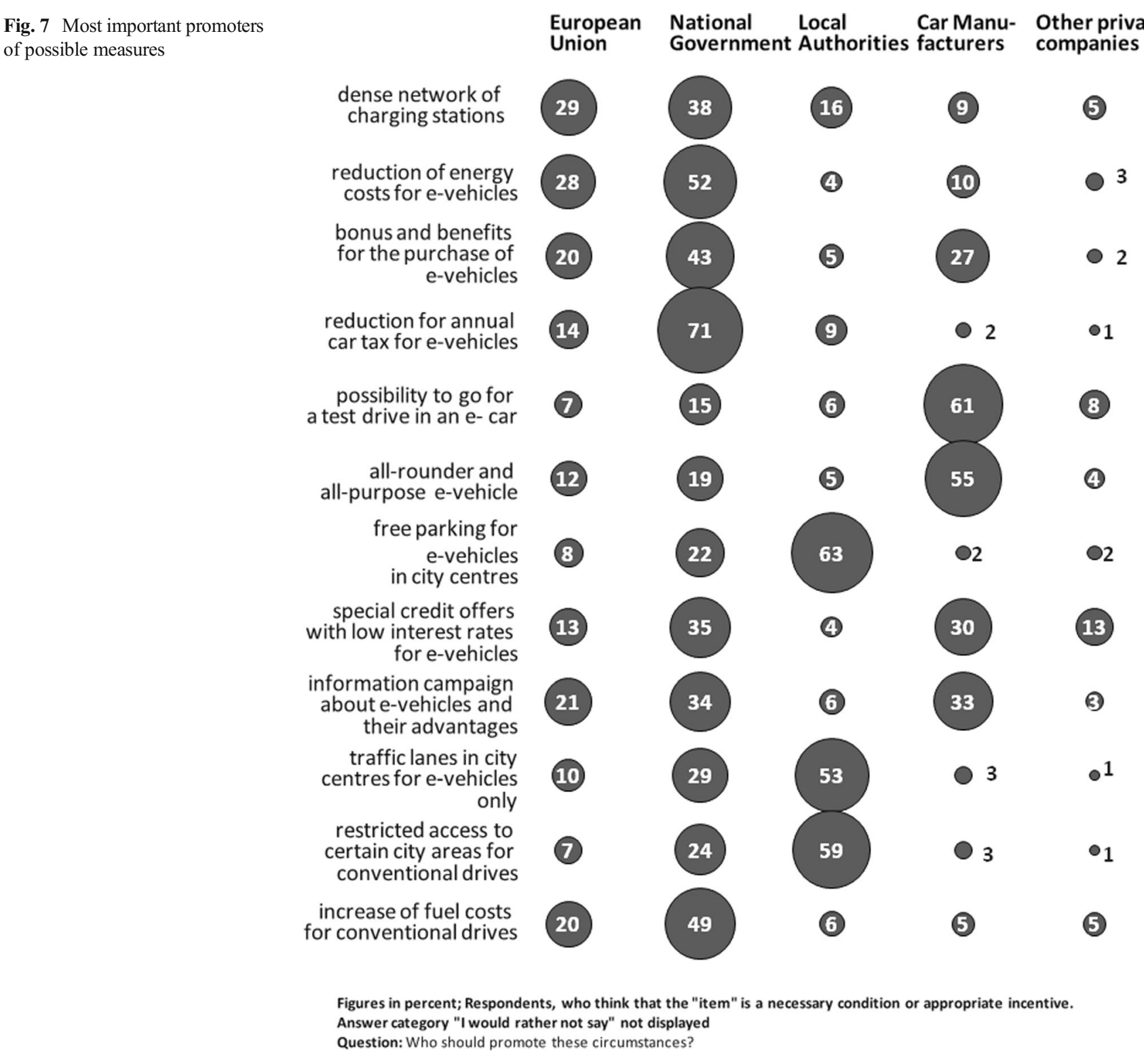

of special traffic lanes for electric cars. Car manufacturers can promote electromobility by offering test rides, all-round and all-purpose electric cars, special credit offers with low interest rates for electric cars as well as by promoting information campaigns.

Cooperation between the EU and national governments is required with regard to the two most important measures: implementation of a dense network of charging stations and reduction of energy costs. These two challenges are perceived as national and European sphere of activity respectively. The second important cooperation is conceived between national governments and car manufacturers: offering bonuses and benefits for purchasing an electric car and credits with lower interest rates as well as promoting an information campaign are the fields of activity where these two players are important.

\section{Scenario results}

Within the market analysis, the agent based vehicle market model VECTOR21 (Vehicle Technologies Scenario Model) is used to specify consumer demand and market supply within different electromobility scenarios. VECTOR21 simulates the competition between conventional and alternative powertrains for the new vehicle market. Using relevant costs of ownership, the least cost- and $\mathrm{CO}_{2}$-intensive car is chosen by one of the 900 customer types (Fig. 8). For more methodological details, see [12].

Exemplary for the scenario results of the project, the impacts of political measures on the market penetration of electric vehicles are presented for Germany. The boundary conditions for the market in Germany have been modelled, taking 
Fig. 8 Concept of the agent based market model VECTOR2 1

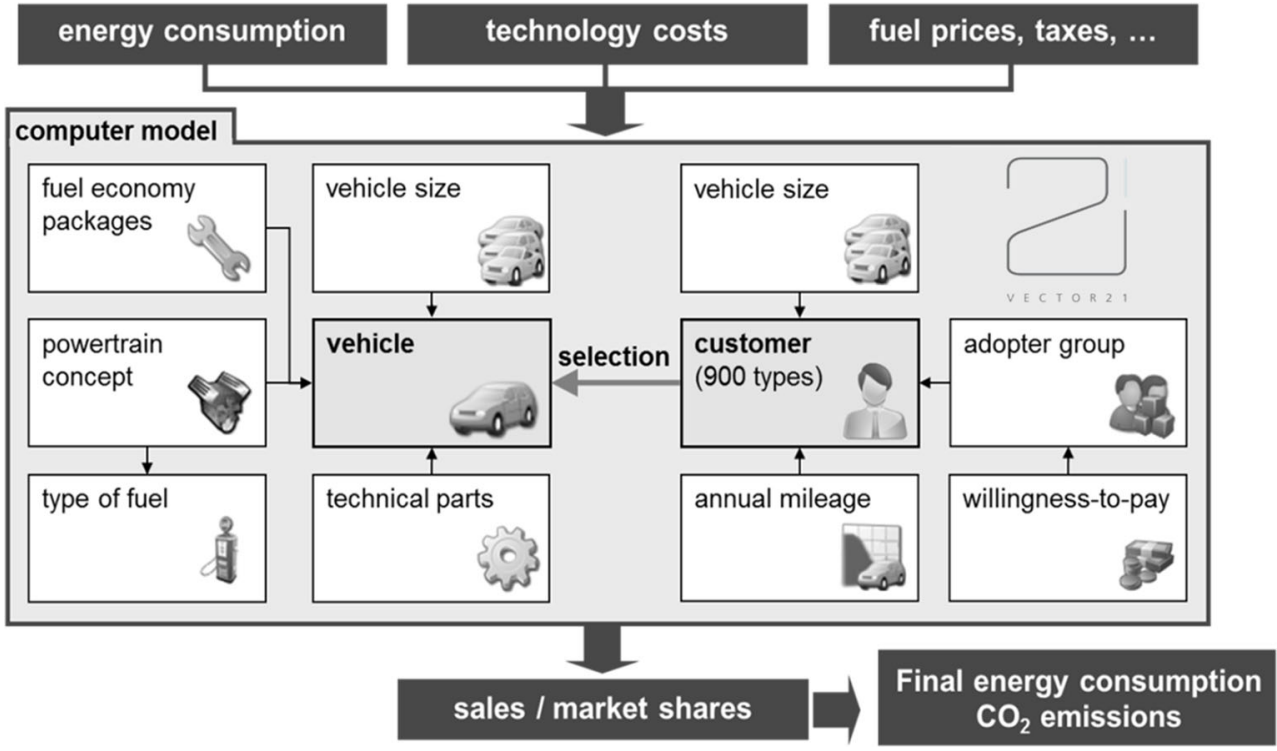

the current situation as well as the development of key parameters like vehicle taxation, incentives, fuel prices and energy consumption, as it can be foreseen from today, into account. Hence, a business as usual scenario $(\mathrm{BaU})$ was calculated for the German market from 2015 until 2030. In a second step, an alternative, policy driven scenario (PoD) has been developed, in which several measures have been introduced to fasten the market penetration of EV: Relating to the results from the customer survey, the three most important factors have been addressed. The expansion of charging infrastructure was accelerated by $10 \%$. The electricity price for charging an electric vehicle was lowered by removing the renewable fee (so-called "EEG-Umlage", in $20156.17 € \mathrm{ct} / \mathrm{kWh}$ ). The purchase costs of electrified vehicles (plug-in hybrid electric vehicle (PHEV), range extended electric vehicle (REEV), and battery electric vehicle (BEV)) were lowered by $1,500 €$ by tax exemptions or purchase premiums for a period of 5 years (2016-2020). Since some of the high rated factors in the customer survey address other, non-monetary measures like information campaigns, it was assumed that the willingness-to-pay for electric vehicles would be $10 \%$ higher than in the base scenario [13].

Due to the chosen measures, the number of electrified vehicles sold until 2030 increased significantly in the PoD scenario in comparison to the $\mathrm{BaU}$ scenario (Fig. 9). In particular, a noticeable market penetration takes place earlier and the cumulated sales reach almost one million electric vehicles already at the end of 2020, compared to 2025 in the $\mathrm{BaU}$ scenario. In addition, a faster growth of electric vehicles sales can be seen in the following years.

\section{Conclusion}

The results from the European wide eMAP consumer survey show a relatively high awareness of the consumers of electric vehicles. Nevertheless, potential customers have high expectations regarding the comfort and range of an electric vehicle. One of the most important barrier and obstacle for a broad market uptake are the currently high purchase prices for this new technology since not all respondents were aware of the lower operating costs of electric vehicles. Consumers are also not convinced of the environmental benefits of these new cars, which is partly understandable regarding the current electricity mix in European countries. If it comes to sacrifice financial resources for the reduction of $\mathrm{CO}_{2}$, most potential consumers would rather have a lower or average purchase price than an environmental friendly car. Therefore, it seems quite necessary to make electric vehicles from a customer's standpoint more attractive. To reach a broader acceptance of electric vehicles several private and governmental measures can be used. From the customer's perspective a dense network of charging stations and financial measures, such as tax and energy cost reductions are vital prerequisites in order to convince them to buy an electric vehicle. Also test drives and more information can decrease the information gaps of consumers about

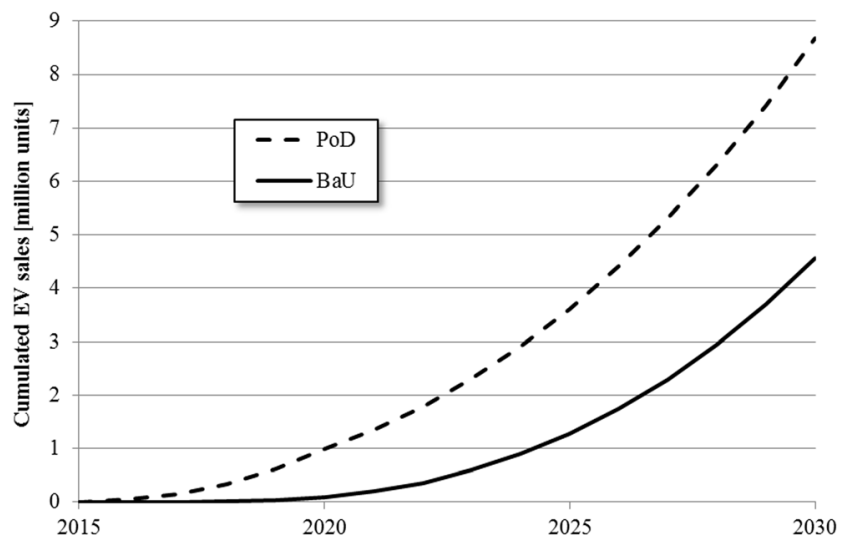

Fig. 9 Cumulated electric vehicles sales in Germany in the $\mathrm{BaU}$ and the PoD scenario 
comfort, safety, range limitations and operating costs of this new drive technology. During the interviews it was apparent, that the most important stakeholders for the promotion of electric vehicles are the national governments and the EU. Especially the charging infrastructure as well as the financial incentives should be guaranteed by the governmental side. But on the other side, the consumers also expect more information and a better supply of car models from the automotive industry. Finally, it has been proven within a scenario based market model for Germany that the use of asset of different promotion measures by the national government can enhance the market share of electric vehicles substantially until 2030 . The example of Norway has shown that tax exemptions can raise the stock of electric vehicles relatively fast. Since the current policy in Germany mainly supports research initiative, showcase projects and non-monetary measures, such as the planned benefits of free parking as well as the use of bus lanes in city centres but only to a lesser degree direct financial incentives, the broad public acceptance of electric vehicles will be probably lower than expected. In the end, the market success of electric vehicles will be determined by the change of the customer's purchase decisions from conventional cars to electric vehicles.

Open Access This article is distributed under the terms of the Creative Commons Attribution 4.0 International License (http:// creativecommons.org/licenses/by/4.0/), which permits unrestricted use, distribution, and reproduction in any medium, provided you give appropriate credit to the original author(s) and the source, provide a link to the Creative Commons license, and indicate if changes were made.

\section{References}

1. European Commission (EC) (2011) White paper - Roadmap to a single european transport area - Towards a competitive and resource efficient transport system, COM (2011) 144 final. Brussels, 28.3.2011
2. Gruschwitz D, Hölscher J, Bühne JA, Gis W, Waśkiewicz J, Balke I, Järvi T, Auvinen H (2014) D4.1 Results of consumer survey and fleet owner interviews on electric vehicles. The eMAP project (electromobility - scenario based Market potential, Assessment and Policy options). Bonn

3. European Parliament (EP), Directorate-General for Internal Policies, Policy Department Economic and Scientific Policy, Industry, Research and Energy (2010) Challenges for a european market for electric vehicles, Brussels

4. Tsang F, et al (2012) Bringing the electric vehicle to the mass market, a review of barriers, facilitators and policy interventions. Working paper WR-775. Cambridge

5. National Research Council - Committee on Overcoming Barriers to Electric-Vehicle Deployment, Board on Energy and Environmental Systems, Division on Engineering and Physical Sciences, Transportation Research Board (2013) Overcoming barriers to electric-vehicle deployment - Interim Report. Washington

6. European Commission (EC) (2013a) EU launches clean fuel strategy. Press Release. Brussels, 24 January 2013

7. European Commission (EC) (2013b) Proposal for a directive of the european parliament and of the council on the deployment of alternative fuels infrastructure, $\operatorname{COM}(2013) 18$ final. Brussels, 24.1.2013

8. Eurostat (2013) Mehr als $60 \%$ der Personen in der EU28 nutzen täglich das Internet. Press release, 18.12.201, Online: http//:epp. eurostat.ec.europa.eu/cache/ITY PUBLIC/4/18122013-BP/DE/418122013-BP-DE.PDF

9. Heinl F, Recker C, Bühne JA, Kurte J, Esser K, Baum H, Auvinen H, Järvi T, Schirokoff A, Gis W, Waśkiewicz J, Pawlak P, Balke I (2013) D1.1 Report on technological and economic background of electromobility, its major stakeholders, research questions addressed, and expected project targets the eMAP project (electromobility - scenario based Market potential, Assessment and Policy options), Cologne

10. Department for Transport (2012) The victorian electric vehicle trial, environmental impacts of electric vehicles in Victoria. Melbourne

11. ACEA (2014) Overview of purchase and tax incentives for electric vehicles in the EU. Brussels

12. Mock P (2012) Entwicklung eines Szenariomodells zur Simulation der zukünftigen Marktanteile und CO2-Emissionen von Kraftfahrzeugen (VECTOR21), Stuttgart

13. Kugler U, Schimeczek C, Klötzke M, Schmid S, Gis W, Järvi T, Auvinen H (2015) D6.2 Scenario report the eMAP project (electromobility - scenario based Market potential, Assessment and Policy options), Stuttgart 